\title{
REFLEXIONES SOBRE EL CONCEPTO DE «YOD*
}

\author{
MARIO BARrA Jover.
}

Con la lectura del manual de Ariza ${ }^{1}$ sobre la fonologia diacrónica del español, se nos ha planteado de nuevo la necesidad de revisar no la descripción de la acción de la yod en español, sino el concepto mismo. Aunque pueda parecer tarea gratuita, quizá no esté de más si nos ayuda a enfocar desde otro punto de vista algunas de las explicaciones que sobre la yod son habitualmente proporcionadas y que, en lo esencial, son ciertas. Por otra parte, no queda tampoco fuera de lugar recordar que para todo estudiante de filología, el asunto de la yod puede rozar en ocasiones el limite de lo fantasmagórico.

Para retomar las primeras lineas, Ariza ${ }^{2}$ nos dice que "la yod es un sonido palatal semivocálico o semiconsonántico, más cerrado que cualquier /i/ puramente vocálica". Con ello no hace más que seguir una larga tradición ${ }^{3}$. Nuestro objetivo en estas líneas es

a) Valorar las implicaciones de asumir la yod como objeto material, es decir, como sonido aislable.

b) En consecuencia, examinar los casos en los que se puede producir una deformación de los datos reales.

c) Examinar, asimismo, las asimetrías que pueden encontrarse en la descripción de la palatalización en español. Por ejemplo, el tratamiento absolutamente distinto de GN/NN $>\tilde{n}$.

d) Proponer dos posibles soluciones no incompatibles, siendo la una de tipo sincrónico, diacrónica la otra, a saber:

- "Yod" es un rasgo palatal y no un sonido palatal.

- "Yod" es todo proceso de palatalización.

Esto puede parecer trivial o demasiado evidente, pero lo más difícil de las trivialidades o de las evidencias es verlas.

1 Manuel Ariza, Mamual de fonologia histórica del español, Madrid, Síntesis, 1990.

Op. cit., pág. 17.

$3 \mathrm{Ni}$ que decir tiene que se trata de una larga tradición que afecta a toda la gramática romance y a la clásica, que tomaron el término de la décima letra del antiguo alfabeto fenicio. 


\section{IMPLICACIONES DE LA YOD COMO SONIDO AISLABLE.}

Habria que distinguir entre el hecho patente de que existen /i/ semiconsonánticas y semivocálicas, bien caracterizadas articulatoriamente ${ }^{4}$ y acústicamente $^{5}$, y el que todo aquello que llamamos "yod" corresponda a tales sonidos. Es decir, si por "yod" entendemos sólo las semiconsonantes (o semivocales; cuando utilicemos el primer término incluimos el segundo, momentáneamente y por comodidad) las cosas cambian, porque se trata de una simple sinonimia. Es más, en los tratados de fonética o fonología sincrónica, el término "yod" no parece algo necesario ".

Esto último nos abre, en parte, las puertas para el razonamiento. La yod parece algo más que un término de la jerga diacrónica. Se trataría de la presunción de la existencia diacrónica de un sonido, basándose en que existe en el sistema sincrónico. Dicho de manera figurada, la yod, en ciertos casos ${ }^{7}$, sería una "semiconsonante fantasma". Trabajos como el de Penny ${ }^{8}$ muestran que, de todas formas, puede caerse en este mismo tipo de reproducción sin necesidad de utilizar el término "yod" (el autor habla de palatal-glide). Si se tratase de una simple reconstrucción, no habría nada de especial; sin embargo, hay otras implicaciones, más profundas, que son las que nos interesan.

Pensemos en tres casos que podrían suponer una escala: $\mathbf{v}$ i n e a, o c u lu y ligna. En el caso de vinea es fácil que la semiconsonante sea una realidad; en el caso de oculu sólo una reconstrucción ligeramente imaginativa permite ver tal sonido palatal; por último, el caso de $1 \mathrm{ig} \mathrm{n}$ a exige recurrir a la manipulación más visible (volveremos a ello más abajo; aqui nos limitamos a presentarlo). Es más, la reconstrucción de una evolución de este tipo, que prevé la existencia de la tal semiconsonante fantasma, supone una concepción del cambio fonético ${ }^{9}$ que se ha revelado cada vez más discutible. Incluso se trata en ocasiones de intentos de explicar el cam-

4 Cfr. Tomás Navarro Tomás, Manual de pronunciación española, Madrid, CSIC, 1982, § 49, y Eugenio Martínez Celdrán, Fonética, Barcelona, Teide, 1984, pág. 167.

s Cfr. Martínez Celdrán, op. cit., pág. 279.

- Emilio Alarcos, Fonología española, Madrid, Gredos, 1965, parte sincrónica; Antonio Quilis, Fonética acústica de la lengua española, Madrid, Gredos, 1981; Navarro Tomás, op. cit.; Martínez Celdrán, op. cit.

$7 \mathrm{Y}$ hacemos hincapié, para no dar lugar a confusiones, en que hay casos de "yod" que son puras y simples semiconsonantes. Tal sería el caso, en la terminología de Menéndez Pidal (Manual de gramática histórica española, Madrid, Espasa Calpe, 1964) de la yod primera, en tanto que un espectrograma de palabras como folio o palio revela los formantes específicos de estos sonidos.

8 Ralph W. Penny, A History of the Spanish Language, Cambridge, Cambridge Univ. Press, 1991.

- Bien representada por trabajos como el de Amado Alonso, Dc la pronunciación medieval a la moderna en español, Madrid, Gredos, 1976. 
bio paso a paso para justificarlo fisiológicamente, para después, por asociación, tomar los distintos pasos por estados reales que se suceden diacrónicamente. Como muestran trabajos como el de Frago ${ }^{10}$, concebir el cambio como algo gradual es difícilmente aceptable. La concepción más realista es que aparecen variantes idiolécticas que acaban convirtiéndose en variantes sociológicas, para llegar a imponerse frente a los demás alófonos ".

$\mathrm{Si}$ aceptamos esta segunda consideración, debemos también aceptar que una evolución del tipo oculu, en la que se propone un estadio en el que existe un sonido yod aislable es apenas sostenible. Pero esto nos lleva al siguiente apartado.

\section{Casos de deformación de los datos.}

Como decíamos, el problema más importante que plantea la tradicional concepción de la yod es el de presentar evoluciones que pueden perder el rango de "reconstrucción" para acercarse al de simple invención de un proceso. En este sentido hay que tratar (y siempre sin salirnos del cuadro clásico de Menéndez Pidal) ${ }^{12}$ los casos de oc ulu, vetulu, ligna, strictu, habida cuenta de que en ellos es improbable la detección de un estadio en el que aparezca o semiconsonante o semivocal.

Lo primero, en este caso, es revisar la importancia que se les pueda asignar a los textos más antiguos. Menéndez Pidal ${ }^{13}$ nos ofrece una exposición ejemplar del esfuerzo gráfico que se puede observar en los primeros testimonios escritos del español. Así, el hecho de que las grafías $i$ o $y$ o $j$ puedan aparecer en tales documentos es, como el mismo Menéndez Pidal muestra, un claro ejemplo de cómo un escriba se valía de los medios a su alcance para, con ellos, reproducir sonidos que no contemplaba el sistema gráfico al uso. Muestra sobradamente conocida de esto, el fonema / $\mathrm{n} /$ cuenta con $n i, i n, n g$,

10 Juan A. Frago, "Valor histórico de las alternancias grafémicas en los fonemas del orden velar", RFE, LXV, 1985, págs. 273-304. Y es sólo un ejemplo, tomado porque el autor insiste en ello. Recuérdese que en estos términos explica Alarcos, op. cit., página 268 , la $f$-. Además, no creemos equivocarnos al pensar que es así como debe entenderse la concepción desarrollada magistralmente por Menéndez Pidal, Orígenes del español, Madrid, Espasa Calpe, 1950, § 112, a propósito del estado latente. Cfr. al respecto Paul Lloyd, "The Contribution of Menéndez Pidal to Linguistic Theory", Hispanic Review, 38, págs. 14-21.

11 La idea explícita y presentada como modelo teórico de descripción, puede verse, sobre todo, en William Labov, Sociolinguistic Patterns, Philadelphia, Univ. of Pennsy1vania, 1972. Emilio Ridruejo, Las estructuras gramaticales desde el punto de vista histórico, Madrid, Síntesis, 1989, pág. 12, la acepta también para el cambio de las estructuras gramaticales.

12 Op. cit., 1964, pág. 49.

13 Op. cit., 1950 , págs. $45-70$. 
$g n, n i g, n, n n^{14}$. Si después de ello, seguimos considerando que el testimonio gráfico puede implicar cualquier presencia de la yod como sonido, estamos rechazando una evidencia. En consecuencia, una grafía li para / $1 /$ no tiene por qué representar una realización [1j]. Se impone, sin embargo, un paréntesis para que lo anterior no dé lugar a equívocos. El estudio de la grafía se manifiesta como único método válido para el estudio del cambio fonético. Hay, por tanto, que recordar los trabajos fundamentales de Frago ${ }^{15}$ sobre los cambios más importantes del español, o los lúcidos hallazgos de Blake sobre la evolución de la $f^{-16}$. Lo esencial es que para ambos estudiosos no estamos ante pasos intermedios de un proceso sino ante manifestaciones de variantes concurrentes que se verifican por contraste. En este sentido ${ }^{17}$ las grafias sirven, independientemente del sonido que aparentemente representen, para establecer la cronología de la extensión de la variante innovadora. Esta manera de pensar cambia mucho las cosas.

A modo de primera conclusión, podríamos decir que está claro que en ciertos casos aparecen semivocales y semiconsonantes como realizaciones alternativas y atestiguadas en variantes coetáneas (feito/fecho, muito/mucho). Las distintas variantes actuales repartidas por dialectos y lenguas de la peninsula nos lo garantizan, así como los ejemplos en los que el proceso siguiente no se ha verificado (p. ej., buitre). Bastante más difícil es, sin embargo, aceptar la existencia de una realización [feico] por el hecho de que sea posible atestiguar feicho. Esta grafía sería muy similar a la nig de la $/ \mathrm{n} /$, a saber, el carácter palatal se manifiesta redundantemente. Hay otros casos, como el de lig na, en los que tampoco contamos con garantía alguna de la exis-

14 Ibid., págs. 49-52.

15 Juan A. Frago, “Nueva contribución a la historia del reajuste fónico del español moderno", Cwadernos de Filología, 2, 1981, págs. 53-74; "El reajuste fonológico del español moderno en su preciso contexto histórico: sobre la evolución $/ \check{s}, \grave{z} />/ \mathbf{x} /$ ", en Serta Philologica F. Lázaro Carreter, I, Madrid, Cátedra, 1983, págs. 219-230; “Materiales para la historia de la aspiración de la /-s/ implosiva en las hablas andaluzas", en Lingüistica española actual, 5, 1983, págs. 153-171; "De los fonemas medievales / $\hat{\text { s, }}$ z/ al interdental fricativo $/ \theta /$ del español moderno", en Philologica Hispariense in $\mathrm{Ho}$ norem M. Alvar, Madrid, 1983, págs. 205-216; "Valor histórico de las alternancias grafémicas en los fonemas del orden velar", RFE, LXV, 1985, págs. 273-304; “El seseo entre Andalucía y América", RFE, LXIX, 1989, págs. 277-310.

16 Robert J. Blake, "Aproximaciones nuevas al fenómeno de [f] $>[\mathrm{h}]>[\emptyset]$ ", en Manuel Ariza et al (eds.), Actas del I Congreso Internacional de Historia de la Lengua Española, I, Madrid, Arco/Libros, págs. 71-82; "Radiografía de un cambio lingüístico de la Edad Media", RFE, LXIX, 1989, págs. 39-59. De hecho, debemos a este autor la primera posibilidad de una cronología absoluta de la $f$ - en lo que se refiere al paso de la vacilación entre $[f / h / ø]$ a un estado de fijación de [f] frente a la vacilación [h/ø]. Las reservas de Ariza, op. cit., pág. 114, ante la hipótesis de Blake no están explicadas.

17 Cfr. Blake, op. cit., y Roger Whright, "La función de las glosas de San Millán de Silos", en Bouvier et al (eds.), Actes du XVIİme Congrès International de Linguistique et Philologie Romanes, 9, Université de Provence, 1986, págs. 211-219. 
tencia de semiconsonante. De hecho, y a modo de ejemplo, Lathrop dice que "aparentemente (el subrayado es nuestro), el grupo GN evolucionó de la manera siguiente: [gn $>$ yn $>$ n] ". Esto nos lleva de nuevo a lo dicho al principio : una "yod" puede haber sido un sonido aislable, pero no tienen por qué serlo todos los casos de "yod" que describimos.

Pero lo dicho hasta aqui carece de carácter definitivo en tanto que es discutible. Falta tratar otro aspecto que muestra que el concepto de "yod" origina tratamientos asimétricos.

\section{Los Casos DE tRATAMIENTos asimétricos.}

Vamos a pasar ahora revista a ciertos casos que han sido apartados de la yod por razones que encuentran justificación en lo expuesto hasta ahora. Antes de nada, hay que considerar el lugar que le asigna Menéndez Pidal en su manual. Nos damos cuenta, así, de que su visión de la yod está en función de la inflexión vocálica o, dicho de otra forma, proporciona una explicación a las evoluciones "irregulares". Tener esto en cuenta ayuda a comprender las observaciones que siguen.

La yod primera y segunda nos ofrecen el caso más notorio. $\mathrm{M}$ in a c i a $>$ amenaza es un ejemplo de yod porque permite localizar una $/ \mathrm{j} /$. Sin embargo, circa > serca es tratado como un caso de "palatalización" (y no hablamos de Menéndez Pidal, sino del conjunto de los tratados diacrónicos). Lo mismo es aplicable a $1 \mathrm{ign}$ a $>$ leña frente a a $\mathrm{nnu}>a \tilde{n}$. La pregunta es inevitable: ¿cómo resultados similares son tratados bajo rótulos distintos? Quizá sea el caso de circa el que nos manifieste más claramente que la razón reside en la auténtica imposibilidad de imaginar un estado intermedio que conduzca al sonido consonántico palatal a través de una semiconsonante que no puede existir por razones evidentes.

Otro caso similar es el que deja fuera de la yod la evolución LL $>\bigwedge_{v} /$. Vemos, pues, que las dos palatales procedentes de geminadas (LL / NN) quedan aparte.

Añadamos a lo anterior el tratamiento de los grupos de oclusiva más líquida en posición inicial. Aunque para algunos autores pueda hablarse de yod ${ }^{19}$, parece que en este caso se acepta una palatalización sin semiconsonante fantasma, tal y como lo expone el mismo Torreblanca ${ }^{20}$. Otro tanto sucede cuan-

18 Thomas A. Lathrop, Curso de gramática histórica española, Barcelona, Ariel, 1984, pág. 127.

10 Véase el resumen de Máximo Torreblanca, "La evolución $/ \mathrm{kl}-, \mathrm{pl}-, \mathrm{fl}-/>/ 1-/$ en español", en $R F E$, LXX, 1990, págs. 317-327.

20 Ibid., pág. 325. 
do, en interior de palabra, estos grupos tienen un resultado africado (i m plere $>$ henchir) y, aún más llamativamente, cuando la africada procede de un grupo cons + c's ( $\mathrm{mancula}>$ mancha, concula $>$ concha). De hecho, Lathrop ${ }^{21}$, cuando trata de la africada, no utiliza el término "yod" en ningún momento.

Hay, además, otra asimetria que afecta a toda la concepción de la yod. Se trata de la relacionada con una metátesis que implica, simplemente, la aparición de diptongos que siguen una evolución normal. Uno puede preguntarse si no se trata de una falta de coherencia por dos razones:

a) Afirmamos que un proceso de palatalización inflexiona a la vocal precedente por diptongación de un hiato (y sus implicaciones) sin mediar metátesis y después lo comparamos con casos en los que no hay tal diptongación, sino la aparición de un diptongo distinto que monoptonga. Así, ne r vi u > nervio se compara con a lta ri u > otero.

b) Dentro del caso de la metátesis se trata de modo similar un caso de monoptongación ( $\mathrm{AI}>e$ ) y un caso de conversión en diptongo creciente (oi $>$ $u e)$. Es ya dificil buscar la palatalización, o incluso la inflexión, en el primer caso; pero imposible en el segundo si nos atenemos a un concepto estricto de inflexión. Suponemos, entonces, que "inflexión" debe aplicarse a los casos $\mathrm{AU}>o$ e ie $>i$, con lo que llegamos a que "inflexión" deje de relacionarse con "palatalización" y la idea de "yod" se diluye aún más.

\section{Conclusión.}

Nuestra conclusión es que el tratamiento de la yod en términos de sonido aislable identificado con semivocal o semiconsonante da lugar a su inaprehensibilidad como proceso fonético. Por muy bien descritos que estén, y lo están, sus efectos, no tenemos claro el asunto del que hablamos.

Se confunden bajo el mismo rótulo:

a) Procesos de palatalización consonántica que conllevan (n octe $>$ noche) o no (fortia > fuerza) inflexión de vocales, a través de un sonido [j] o [i].

b) Procesos de inflexión sin palatalización consonántica (ne r vi u > nervio).

c) Procesos de metátesis que ni palatalizan ni, en sentido estricto, inflexionan; además de ofrecer resultados distintos ( $\mathrm{b}$ a $\mathrm{s}$ i u $>$ beso, a u $\mathrm{g} \mathrm{u}$ ri u > agüero).

Sin embargo, quedan excluidos:

a1 $O p$. cit. 
a) Procesos de palatalización consonántica que conllevan ( $\mathrm{fe} \mathrm{c} \mathrm{i}>$ hice) o no ( c a rcere $>$ cárcel) inflexión de vocales sin mediar un sonido [j] o [i].

b) Procesos de palatalización donde la inflexión no interviene, pero que ofrecen resultados similares a casos de yod $(\mathrm{mancula}>\operatorname{mancha}, \mathrm{cla}-$ mare $>$ llamar, an $\mathrm{nu}>a \tilde{n} o$ ).

c) Casos de reducción de diptongos que implicarán algún tipo de rasgo palatal (fronte $>$ fruente $>$ frente) o de cierre $(\mathrm{sella}>$ siella $>$ silla).

A nuestro modo de ver, se debe aceptar una visión más amplia de la yod. Es necesario mantener el término por tơda la tradición que implica, pero asumiendo su sentido. Así, tal y como hemos propuesto en nuestra introducción, creemos conveniente que la yod sea comprendida como una marca de palatalización, es decir, un formante palatal que procede de varios lugares (una semiconsonante entre ellos) y que puede incidir en consonante y vocal (noche, hice), sólo en consonante (fuerza, año) o sólo en vocal (nervio, durmiendo). Creemos que, para mayor claridad, seria deseable excluir de esta definición los procesos de metátesis en tanto que sus efectos son incluibles en otras tendencias generales (monoptongación, asimilaciones de vocales o transformaciones de diptongos). Con ello, la yod, la semiconsonante y la semivocal quedarían relacionadas pero no identificadas.

Llegamos, en consecuencia, a la otra conclusión, la estrictamente diacrónica: la yod es más comprensible como proceso de palatalización, sin más ${ }^{22}$.

a Lathrop, op. cit., pág. 366, habla de "yotización", pero entiende por ello solamente evoluciones del tipo sedeA $>$ seya. 